\title{
Work related spinal cord injury, Australia 1986-97
}

\author{
P O’Connor
}

\begin{abstract}
Objectives-Little has been published before on the epidemiology and prevention of work related spinal cord injury (SCI). This study is the first national population based epidemiological analysis of this type of injury. It presents that largest case series ever reported.

Setting-The study utilises information from the Australian Spinal Cord Injury Register, which has full coverage of the population.

Methods-All newly incident cases of SCI from 1986 to 1997 were considered.

Results-Work related SCI accounted for about $13 \%$ of all traumatic cases of SCI over the period 1986-97. The labour force based incidence rate in Australia averaged four cases per million of population per annum over the period. The rate was highest among those aged 25-34 years (4.9/million) and among farmers (17.0/ million). Nearly half of the cases studied received their injury due to a fall. Motor vehicle crashes were also common and vehicle rollover was the predominant crash type. A high proportion of cases did not receive any compensation for their SCI.

Conclusions-Although rare, SCI is one of the most severe and debilitating injuries that can be suffered in the workplace. As there is no cure for SCI, and the level of impairment does not improve substantially for the vast majority of cases even after rehabilitation, it is arguable that primary prevention should receive substantially greater emphasis.

(Injury Prevention 2001;7:29-34)
\end{abstract}

Keywords: occupational injury; spinal cord injury; epidemiology; compensation

Although rare, spinal cord injury (SCI) is one of the most severe and debilitating injuries that can be suffered in the workplace. However, little has been published in the international medical, and occupational health and safety, literature on the epidemiology of this type of injury. A Medline search revealed only two epidemiological studies focused specifically on SCI in the work force, ${ }^{12}$ neither of which was population based, which prevented the reporting of incidence rates. In contrast there has been much written about return to work and employment after SCI. The imbalance in the literature perhaps reflects the levels of interest in primary prevention versus rehabilitation. As there is as yet no cure for SCI, and the level of impairment does not improve substantially for the vast majority of cases even after rehabilitation, it is arguable that primary prevention should receive substantially greater emphasis.

This study reports on work related SCI, using information from the Australian Spinal Cord Injury Register (ASCIR).

\section{Methods}

ASCIR

Australia was the first country to successfully implement a national population based registry of SCI. All cases of SCI are referred to a small number of specialist treatment units, either immediately or after stabilisation at another hospital. In order to facilitate national and international comparisons, the case definition that has been adopted in Australia for registration of traumatic cases of SCI is the CDC clinical definition: " . . . a case of spinal cord injury is defined as the occurrence of an acute, traumatic lesion of neural elements in the spinal canal (spinal cord and cauda equina), resulting in temporary or permanent sensory deficit, motor deficit, or bladder/bowel dysfunction". ${ }^{3}$

The ASCIR data dictionary was developed in order to maximise the potential for international comparisons, ${ }^{4}$ with data items and classifications selected, as much as possible, on the basis of international standards. ${ }^{56}$ Occupation was coded to the Australian Standard Classification of Occupations, Version I. ${ }^{7}$ Other items conformed to the Australian National Health Data Dictionary. ${ }^{8}$

\section{CASE SELECTION}

The analysis focused on new incidents from 1986-97. Work related cases were identified as those occurring in a workplace and/or where the activity of the person at the time of injury was specified as working for income. Cases involving people working around their own home or undertaking voluntary work outside the home in an unpaid capacity were excluded. Cases who had resolved neurologically before discharge were excluded. The analysis was restricted to cases aged 15-64 years (369 cases), to focus on the primary "working age" group. In Australia, a person may not be engaged in full time work until 15 years of age and the retirement age is 65 years.

\section{Results}

INCIDENCE OF WORK RELATED SCI

Over the period 1986-97, an average of 31 new cases of work related SCI occurred each year in Australia (369 cases in total). Work related SCI accounted for about $12 \%$ of SCI from all traumatic causes over the period. The vast majority of these injuries were unintentional $(97.8 \%$, $\mathrm{n}=361$ ). Five cases were due to assaults in the 


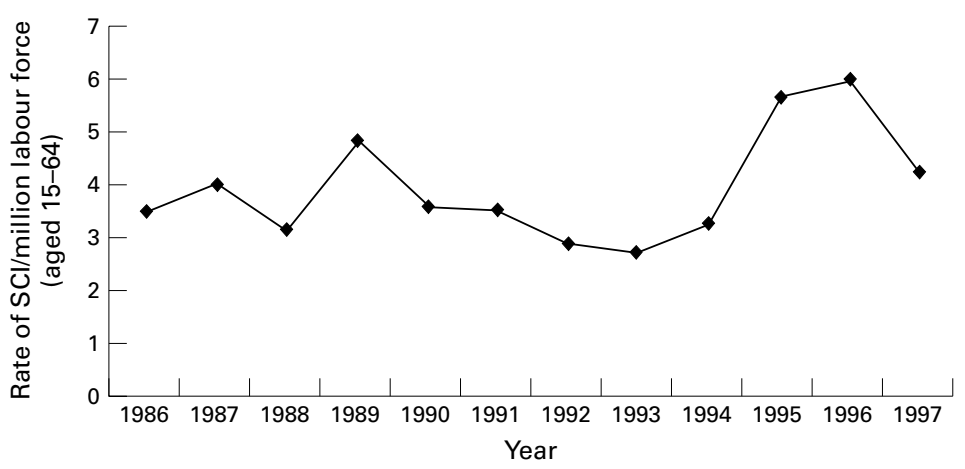

Figure 1 Rate of work related SCI per million labour force, Australia 1986-97.

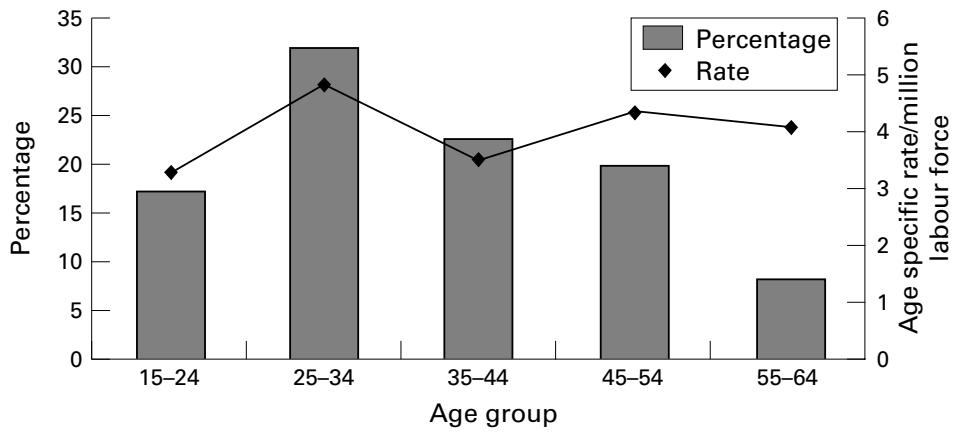

Figure 2 Age distribution of work related SCI, Australia (percentage and labour force based age specific rate averaged over 1986-97).

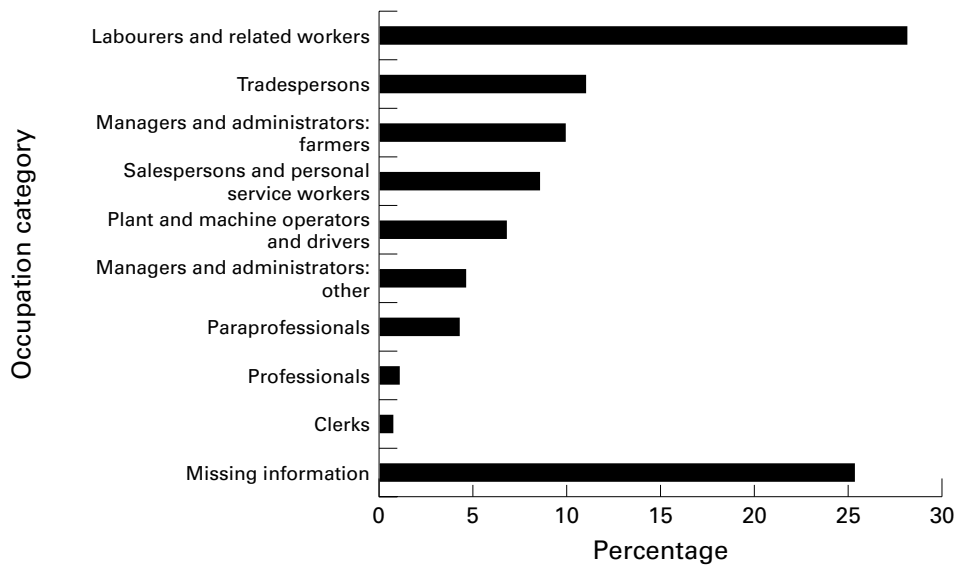

Figure 3 Occupation category of work related SCI, Australia (percentage averaged over 1986-97, age 15-64 years).

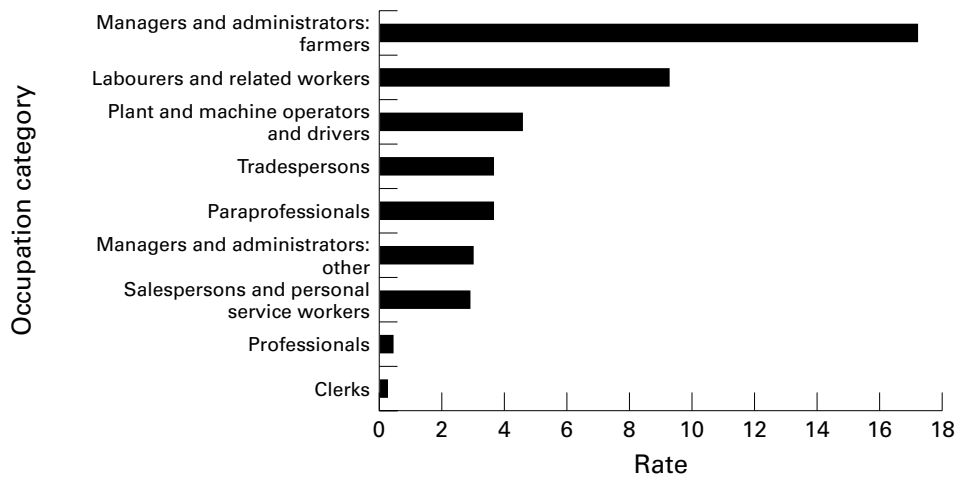

Figure 4 Estimated rate of work related SCI per million labour force by occupation category, Australia (crude rate averaged over 1986-95, age 15-64 years). workplace-all from gunshot wounds, mainly in the lower thoracic region and all resulting in complete transection of the spine. There was one case of self harm occurring as a result of a high fall brought about by an acute psychiatric episode; one case where the SCI was caused as a result of the medical treatment of a work related injury; and one case of unspecified intent.

Figure 1 presents the trend in work related SCI with reference to the size of the Australian labour force. ${ }^{9}$ The average labour force based rate of SCI over the entire period 1986-97 was 4.0/million.

AGE AND SEX

Seventy five per cent of the cases were aged 25-54 years, with the highest proportion aged 25-34 years (fig 2). The labour force based rate of SCI was highest for 25-34 year olds (4.9/million). There was a contrast in the pattern of rates compared with proportions over age.

Ninety five per cent of the cases of work related SCI were male.

OCCUPATION CATEGORY

Analysis of labour force based rates of SCI by occupation category was restricted to the period 1986-95 $(n=283)$ due to changes in the occupation classification from 1996-there was no certain mapping of occupations between the two periods. Over this period, occupation category was missing for $25 \%$ of SCI cases ( $n=72$; fig 3$)$. The highest proportion of cases were labourers and related workers $(28 \%)$, many of whom were construction and mining labourers (8\%), miscellaneous labourers $(7 \%)$, and trades assistants and factory hands $(6 \%)$

In order to provide an estimate of the labour force based rate of SCI by occupation group, cases with missing occupation group were assigned to other occupation groups on a proportional basis. The estimated labour force based rate of SCI was highest for farmers (17.0/million; fig 4), nearly double the rate of the occupation group with the next highest rate (that is, labourers and related workers; 9.2/ million). While tradespersons made up a high proportion of SCI cases, their labour force based rate (3.6/million) was lower than, or equivalent to, other occupation categories that accounted for a lower proportion of casesthat is, plant and machine operators and drivers (4.5/million) and paraprofessionals, which includes police and emergency services workers (3.6/million).

\section{EXTERNAL CAUSE OF INJURY}

The external cause of work related SCI is presented in fig 5 . Almost half of the cases were due to falls (47\%). Falls predominated in each age group (fig 6). The labour force based rate of SCI from falls was an average of nearly 2/million over the period 1986-97. Transport related injury accounted for $25 \%$ of cases, mostly injury to vehicle occupants (13\%). Injury from striking, or being struck or crushed by, an object, machinery, or person was the 


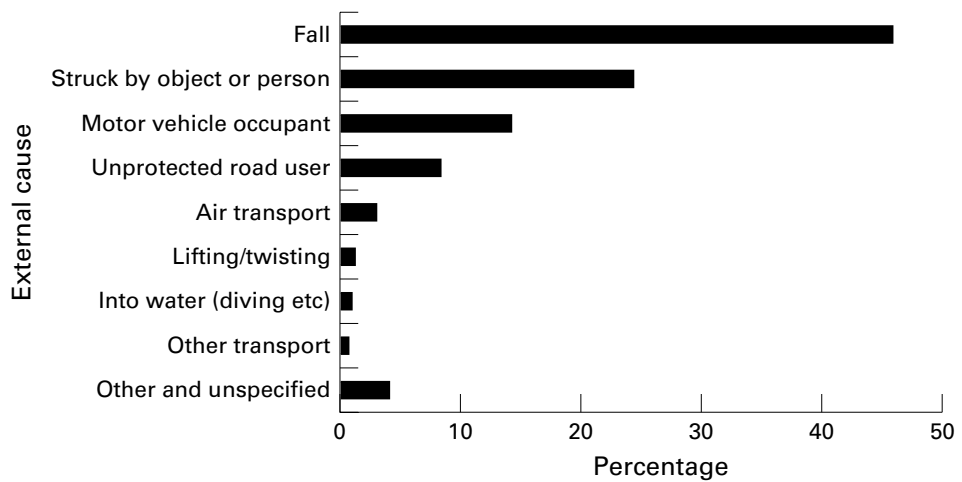

Figure 5 External cause of work related SCI, Australia (percentage averaged over 1986-97, age 15-64 years).

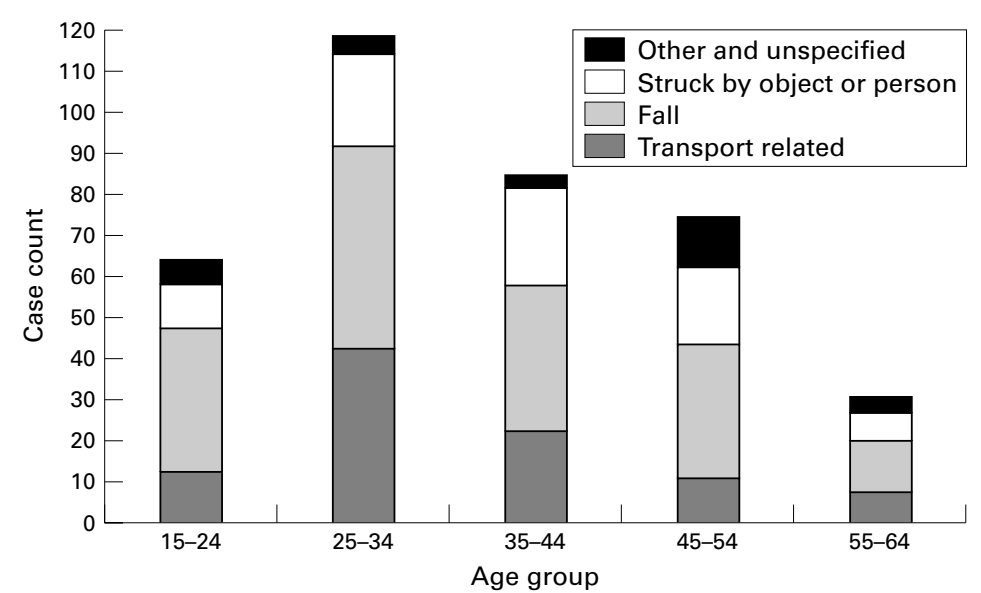

Figure 6 External cause of work related SCI by age group, Australia (total case count, 1986-97).

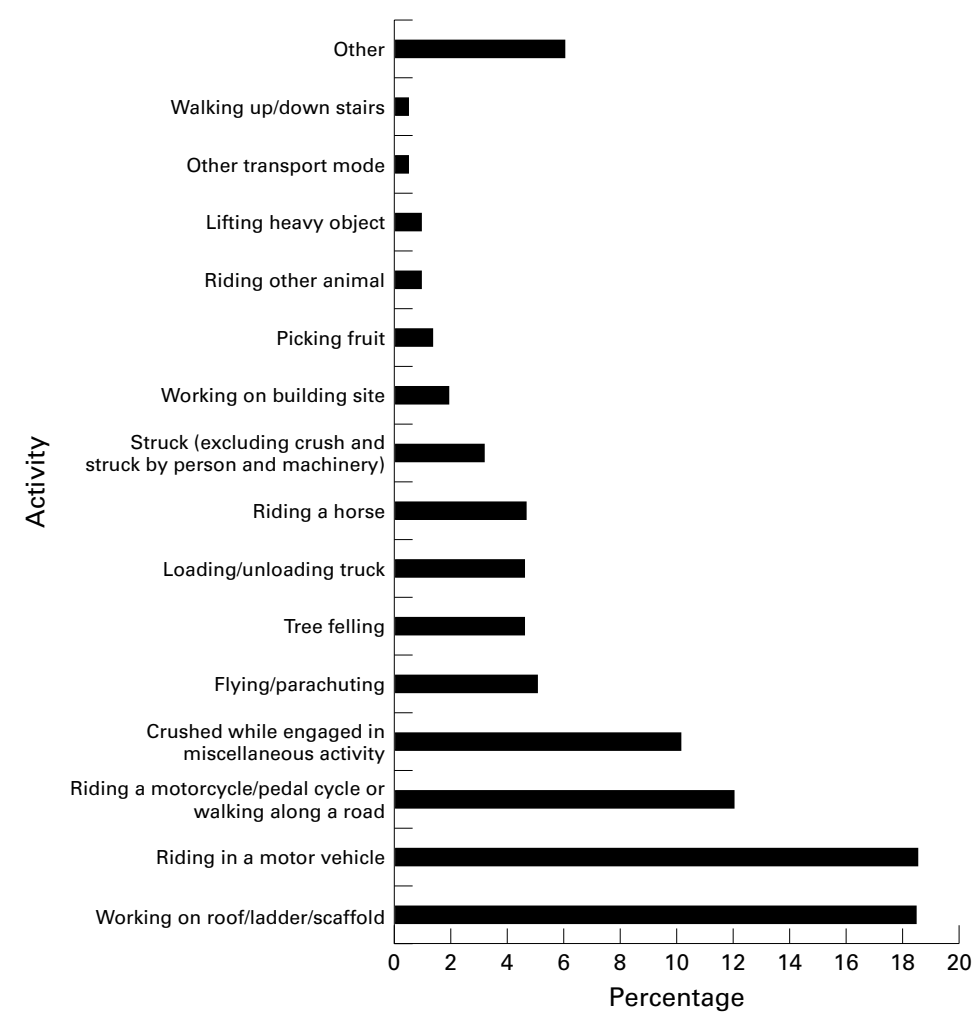

Figure 7 Work related activity undertaken at time of SCI, Australia (percentage averaged over 1992-97, age 15-64 years). external cause of SCI for $24 \%$ of work related cases, two thirds of which were coded according to International Classification of Diseases external cause codes E916-919.

ACTIVITY ENGAGED IN AT THE TIME OF INJURY Information about the activity engaged in at the time of injury was provided in a text description of the injury event, which was reliably reported for cases incident from 1992 ( $n=202$; fig 7 ). The highest proportion of cases were either working on a roof, ladder, or scaffold at the time of injury, and their SCI was caused by a fall $(19 \%)$, or were an occupant in a motor vehicle $(19 \%)$. Of the occupants, the highest proportion was involved in a motor vehicle rollover (38\%; fig 8).

Of the 28 farmers who suffered a workrelated SCI over the period 1986-95, the external causes were falls (12 cases), struck/ crushed by an object or person (11 cases), motorcycle crashes (two cases), motor vehicle crashes (one case), and other causes (two cases). Of the falls, four were from a horse, one each from a silo, fruit picker, roof, and a raised platform, and four from unspecified features. Of the cases that were struck by an object or person (11 cases), the nature of the event was specified for only four cases: two were crushed by falling bales of hay from hay baling equipment, one was hit by a bull, and one was hit by a bullet from a gun as a result of an assault.

\section{NEUROLOGICAL LEVEL AND COMPLETENESS OF} INJURY

The neurological level of SCI at discharge is presented in fig 9. The neurological level of injury was reported for 358 of the 369 cases of work related SCI. Sixty eight per cent of the cases where neurological level was reported were paraplegic and $32 \%$ were tetraplegic. With paraplegia, upper limb function is spared, whereas with tetraplegia there is impairment or loss of motor and/or sensory function in the arms as well as in the trunk, legs, and pelvic organs.

Work related cases were less likely to be tetraplegic than non-work related cases $(31 \% v$ $53 \%$; table 1). This reflected the fact that work related cases had a lower incidence of motor vehicle injuries, which more often involved the cervical segments of the spine causing tetraplegia. Work related motor vehicle cases had a higher proportion of tetraplegia than work related cases not involving motor vehicles $(53 \%$ $v 27 \%$ ); a corresponding difference was not seen for cases that were not work related.

The overall severity of SCI is usually measured by combining the neurological level and extent of injury into four neurological categories (complete tetraplegia, incomplete tetraplegia, complete paraplegia, and incomplete paraplegia). For 11 cases, neurological category was not specified. Of the remaining 358 cases, incomplete and complete paraplegia (35\% and $34 \%$ respectively) were each more than three times as common as complete tetraplegia $(10 \%)$. 


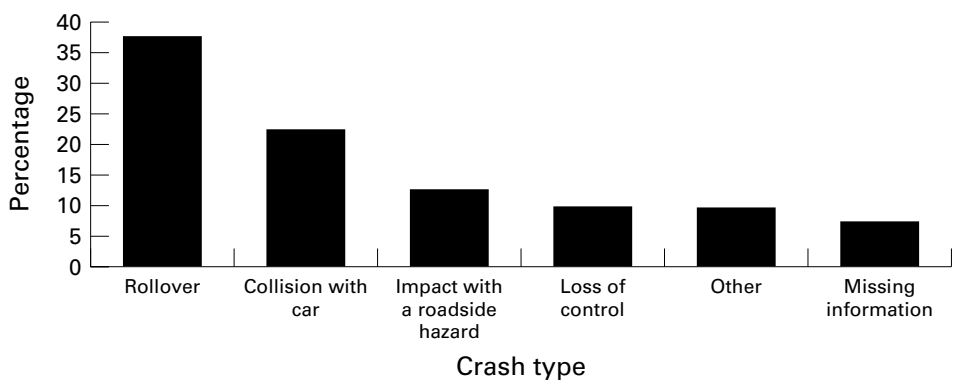

Figure 8 Crash type for work related SCI to motor vehicle occupants, Australia (percentage averaged over 1992-97, age 15-64 years).

Table 1 Neurological level of injury for work related SCI compared with other SCI by external cause of injury, Australia (total case count, 1986-97; age 15-64 years)

\begin{tabular}{lllll}
\hline & \multicolumn{2}{l}{ Neurological level of injury } & \\
\cline { 2 - 3 } External cause & $\begin{array}{l}\text { Tetraplegia } \\
\text { No (\%) }\end{array}$ & $\begin{array}{l}\text { Paraplegia } \\
\text { No (\%) }\end{array}$ & $\begin{array}{l}\text { Missing } \\
\text { No (\%) }\end{array}$ & $\begin{array}{l}\text { Total } \\
\text { No (\%) }\end{array}$ \\
\hline $\begin{array}{llll}\text { Work related } \\
\quad \text { Motor vehicle occupant }\end{array}$ & $27(52.9)$ & $24(47.1)$ & 0 & \\
$\quad$ Other & $86(27.0)$ & $221(69.5)$ & $11(3.5)$ & $31(100.0)$ \\
$\quad 113(30.6)$ & $245(66.4)$ & $11(3.0)$ & $369(100.0)$ \\
$\quad$ Total & & & & \\
$\quad$ Motor vehicle occupant & $526(57.9)$ & $371(40.8)$ & $12(1.3)$ & $909(100.0)$ \\
$\quad$ Other & $670(49.3)$ & $676(49.7)$ & $14(1.0)$ & $1360(100.0)$ \\
$\quad$ Total & $1196(52.7)$ & $1047(46.1)$ & $26(1.2)$ & $2269(100.0)$ \\
Total & $1309(49.6)$ & $1292(49.0)$ & $37(1.4)$ & $2638(100.0)$ \\
\hline
\end{tabular}

The external cause of injury for cases of work related SCI is presented by neurological level in table 2. Motor vehicle occupants most often suffered from injury to the cervical segments of the spine. Unprotected road users most often suffered thoracic level injuries. Falls primarily resulted in thoracic level injuries.

Cases of work related SCI from falls, and from injury to motor vehicle occupants, made up the largest proportion of the most severely injured, that is, those with complete tetraplegia ( $51 \%$ and $24 \%$ respectively).

COMPENSATION FOR WORK RELATED SCI

Reliable information on the compensation status of SCI cases was available in the ASCIR from 1986-89 and also from 1995 (245 cases). These data showed that only $64 \%$ of the work related cases received compensation (worker's compensation or any other compensation) for their SCI.

\section{Discussion}

Work related SCI accounted for about $12 \%$ of all traumatic cases of SCI in Australia over the period 1986-97. Ekong and Tator ${ }^{1}$ and Rosenberg et $a l^{2}$ found similar result in Canada and the USA. The labour force based incidence

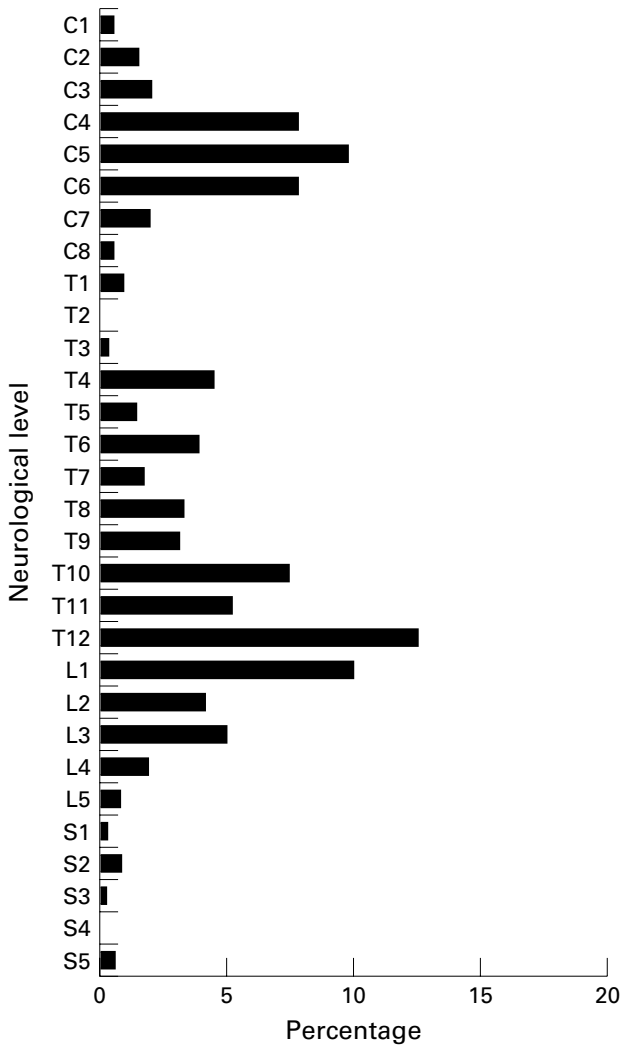

Figure 9 Neurological level of injury for work related SCI, Australia (percentage averaged over 1986-97, age 15-64).

rate of work related SCI in Australia averaged about four cases per million over the period 1986-97. This is the first time that labour force based rates have been reported in the literature.

While the vast majority of work related SCIs in Australia over the period 1986-97 were unintentional $(97.9 \%, \mathrm{n}=381)$, five cases were due to assault. All of the assault related SCIs were from gunshot wounds. The case count was too small to determine whether there was an increasing trend from this cause. From the limited evidence available, it appears that penetrating injury has not increased in Australasia. ${ }^{10}{ }^{11}$ SCI from gunshot wounds is a much more prevalent problem in the United States and its incidence is increasing. ${ }^{12}{ }^{13}$ There are strong legislative controls restricting the availability of guns in Australia. ${ }^{14}$ Semiautomatic weapons and pump action shotguns are prohibited.

The highest proportion of work related cases of SCI in Australia were aged 25-34 years, an age group that would typically expect to have

Table 2 Neurological level of work related SCI by external cause, Australia (total case count, 1986-97; age 15-64 years)

\begin{tabular}{|c|c|c|c|c|c|c|c|c|c|c|}
\hline \multirow[b]{3}{*}{ External cause } & \multirow{2}{*}{\multicolumn{2}{|c|}{$\begin{array}{l}\text { Tetraplegia: } \\
\text { cervical }\end{array}$}} & \multicolumn{6}{|c|}{ Paraplegia } & \multirow{2}{*}{\multicolumn{2}{|c|}{ Total }} \\
\hline & & & \multicolumn{2}{|c|}{ Thoracic } & \multicolumn{2}{|c|}{ Lumbar } & \multicolumn{2}{|l|}{ Sacral } & & \\
\hline & Count & $\%$ & Count & $\%$ & Count & $\%$ & Count & $\%$ & Count & $\%$ \\
\hline Motor vehicle & 27 & 52.9 & 17 & 33.3 & 7 & 13.7 & 0 & 0.0 & 51 & 100.0 \\
\hline Unprotected & 6 & 20.0 & 16 & 53.3 & 8 & 26.7 & 0 & 0.0 & 30 & 100.0 \\
\hline Fall & 51 & 32.3 & 67 & 42.4 & 36 & 22.8 & 4 & 2.5 & 158 & 100.0 \\
\hline Struck/crushed & 18 & 21.2 & 47 & 55.3 & 17 & 20.0 & 3 & 3.5 & 85 & 100.0 \\
\hline Other and unspecified & 11 & 32.4 & 12 & 35.3 & 11 & 32.4 & 0 & 0.0 & 34 & 100.0 \\
\hline Total & 123 & & 163 & & 83 & & 9 & & 358 & 100.0 \\
\hline
\end{tabular}

Note: excludes 11 cases where neurological level of injury was not reported. 
the greater proportion of their working life before them. Evidence from other Australian studies suggests that between $60 \%$ and $70 \%$ do not return to work after their SCI. ${ }^{15}{ }^{16}$ Males predominate in work related SCI, which may reflect their higher employment levels and also the nature of the industries in which they are employed.

Although rare, SCI has a profound effect on the individual and has a substantial economic cost. Walsh and DeRavin estimated that the cost of the long term care of each new case of SCI in Australia ranged from approximately $\$ 602000$ for a paraplegic, \$1 175000 for a tetraplegic, and $\$ 4000000$ for a ventilator dependent tetraplegic. ${ }^{17}$ On this basis, the new cases of work related SCI aged 15-64 years that occurred over the period from 1986-97 can be estimated to have generated a long term care cost of more than $\$ 286$ million in Australia in total, or in excess of $\$ 23$ million each year. A high proportion of this cost is borne by the workers themselves, and the Australian community through the publicly funded health and welfare system, as it has been shown that only $64 \%$ of cases of SCI receive compensation for their injury. The reason why a high proportion of cases does not receive compensation has not been studied before and this warrants attention. All employees in Australia are supposedly covered by a compulsory workers' compensation scheme called "Workcover". ${ }^{18}$ Qualitative research by the author with barristers, lawyers, and medical practitioners involved in SCI legal cases has identified a number of reasons why a person suffering a work related SCI may not receive workers' compensation in Australia: they are self employed and have not taken out personal insurance cover, even though they are required to take out cover for all employees; the workers' compensation scheme is some states does not cover the journey to work; where a worker is not covered by workers' compensation, they may also not be covered by compulsory third party motor vehicle insurance where fault can be proven (for example, where the driver was affected by alcohol, was not wearing a seat belt, or was involved in a single vehicle crash).

Those who have no insurance cover obviously face a more challenging future financially. In addition, it has been shown on numerous measures that patients with SCI who are not eligible for compensation payments have worse outcomes. ${ }^{19} 20$

The labour force based rate of SCI was highest for farmers in Australia (17/million). Studies in Canada and the USA have emphasised the SCIs of construction workers, based on the high representation of this occupational group among work related cases, with no consideration given to the size of the labour force. ${ }^{12}$ Little has been published on the SCIs suffered by farmers. In Australia, most of the SCIs of farmers were due to falls, especially from horses. Friesen and Ekong found that in a Canadian farming district, a high proportion $(32 \%)$ of farming related spinal injuries over the period 1979-86 were caused by tractor mounted front end bale loaders that were used for moving large round hay bales. ${ }^{21}$ These injuries occurred when the loader arms were raised past the horizontal plane causing the bale to roll back onto the unprotected tractor operator. In the present data series, one case of SCI from such a mechanism was reported. Clearly, there is a need for hay baling equipment to be fitted with a safety cage to prevent round hay bales from rolling onto the driver.

Nearly half of the cases of work related SCI in Australia received their SCI due to a fall. Falls from roofs, ladders, and scaffolding were common. Ekong and Tator found a similar result in Canada. ${ }^{1}$ Motor vehicle crashes were also a common cause of work related SCI in Australia, with vehicle rollover being the predominant crash type. Prevention of these injuries requires the removal of the conditions that initiate the rollover event, such as loose road shoulders, ${ }^{22}$ and changes to vehicle design, such as improvement of glazing to prevent ejection, ${ }^{23}$ increasing the resistance to bending of the A pillars and B pillars, ${ }^{24}$ and improvement of seat belt design to prevent vertical movement in the event of rollover. ${ }^{25}$ Recent detailed investigation of vehicle rollovers in South Australia suggests that non-sedan type vehicles (four wheel drive vehicles, light trucks, and vans) have a much greater likelihood of rollover SCI than sedans. ${ }^{26}$ Four wheel drive vehicles, and other vehicles with a high centre of gravity, are more frequently involved in SCI because they have a greater propensity to roll. ${ }^{24}{ }^{27}$ It is therefore of concern that there is the trend in Australia, ${ }^{28}$ and also in the USA, ${ }^{27}$ toward a greater number of non-sedan type vehicles in the car fleet.

Tetraplegia was less common in work related SCI than in other traumatic cases of SCI. Ekong and Tator found a similar result in Canada. ${ }^{1}$ In the present data series this finding reflected the lower incidence of motor vehicle crashes in work related SCI.

Among the issues that warrant further assessment are: the reasons why some occupations have higher labour force based rates of SCI than others; the reasons why falls are so common, and the extent to which they occur under circumstances that do/could come under worker protection rules; the reasons why a relatively high proportion of work related cases of SCI do not receive compensation of any sort; and the extent to which work related SCIs, particularly those due to falls, can be prevented. An in-depth study, at the scene of the injury, which includes an assessment of work practices, causal factors, injury biomechanics, first aid and retrieval measures, would greatly assist in the prevention of work related SCI.

\section{Implications for prevention}

SCI is one of the most severe and debilitating injuries that can be suffered in the workplace. As there is no cure for SCI, and the level of impairment does not improve substantially for the vast majority of cases even after rehabilitation, primary prevention should receive substantially greater emphasis. 


\section{Key points}

- Spinal cord injury (SCI) is one of the most severe and debilitating injuries that can be suffered in the workplace.

- There is no cure for SCI, and the level of impairment does not improve substantially for the vast majority of cases even after rehabilitation, therefore primary prevention should receive substantially greater emphasis.

- A high proportion of the cost of work related SCI is borne by the Australian community as it has been shown that only $64 \%$ of cases of SCI receive compensation for their injury.

- The labour force based rate of SCI was highest for farmers in Australia (17 cases per million). Most of these injuries occurred as a result of a fall, notably from a horse.

- Motor vehicle crashes were also a common cause of work related SCI in Australia, with vehicle rollover being the predominant crash type. Four wheel drive vehicles, and other vehicles with a high centre of gravity, are more frequently involved in SCI because they have a greater propensity to roll. It is a concern that these vehicles make up an increasing proportion of the vehicle fleet in Australia, and also in the USA. Prevention of these injuries requires the removal of the conditions that initiate the rollover event, such as loose road shoulders, and changes to vehicle design, such as improvement of glazing to prevent ejection, increasing the resistance to bending of the A pillars and $B$ pillars, and improvement of seat belt design to prevent vertical movement in the event of rollover.

All workers should be adequately covered by insurance. The existing national insurance system for workers does not provide adequate coverage in Australia.

The labour force based rate of SCI was highest for farmers in Australia (17 cases per million). More attention to severe farm injuries is required.

Motor vehicle crashes were a common cause of work related SCI in Australia, with vehicle rollover being the predominant crash type. Prevention of these injuries requires the removal of the conditions that initiate the rollover event, such as loose road shoulders, and changes to vehicle design (for example, improvement of glazing, increasing the resistance to bending of the A pillars and B pillars, and improvement of seat belt design to prevent vertical movement in the event of rollover). The increasing number of high centre of gravity vehicles (for example, four wheel drives), in the vehicle fleet is a concern, because they have a greater propensity for rollover.
The ASCIR is a cooperative arrangement of the six Australian spinal units and the National Injury Surveillance Unit of the Flinders University Research Centre for Injury Studies (RCIS), funded by the Australian Institute of Health and Welfare.

The National Occupational Health and Safety Commission (NOHSC) financially supported the data analysis work on which the article is based. The assistance of Drs J Mandryk and $\mathrm{T}$ Driscoll in reviewing the report on which the article is based is gratefully acknowledged.

1 Ekong CE, Tator CH. Spinal cord injury in the work force. Can F Surg 1985;28:165-7.

2 Rosenberg NL, Gerhart K, Whiteneck G. Occupational spinal cord injury: demographic and etiologic differences from non-occupational injuries. Neurology 1993;43:1385-8.

3 Thurman DJ, Sniezek JE, Johnson D, et al. Guidelines for surveillance of central nervous system injury. Atlanta: US Department of Health and Human Services, Centers for Disease Control and Prevention, 1995.

4 Research Centre for Injury Studies. Australian spinal cord injury register: data dictionary. Adelaide: Flinders University Research Centre for Injury Studies, AIHW National Injury Surveillance Unit, 1997.

5 Maynard FM Jr, Bracken MB, Creasey G, et al. International standards for neurological and functional classification of spinal cord injury. American Spinal Injury Association. Spinal Cord 1997;35:266-74.

6 World Health Organization. International classification of diseases, 9th revision, clinical modification (ICD-9-CM). Geneva: WHO, 1996.

7 Australian Bureau of Statistics. Australian standard classification of occupations, Version 1. Canberra: ABS, 1992.

8 Australian Institute of Health and Welfare. National health data dictionary. Version 4. Canberra: Australian Institute of Health and Welfare, 1995.

9 Australian Bureau of Statistics. Labour statistics, Australia. (Catalogue No 6101.0). Canberra: ABS, 1996.

10 Sidhu S, Sugrue M, Bauman A, et al. Is penetrating injury on the increase in south-western Sydney? Aust N Z F Surg 1996;66:535-539.

11 Civil ID, King M, Paice R. Penetrating trauma in Auckland: 12 years on. Aust N Z F Surg 1998;68:261-3.

12 Stover SL, DeLisa JA, Whiteneck GG. Spinal cord injury. Clinical outcomes from the model systems. Maryland: Aspen Publishers, 1995: 35-40.

13 Carroll CM. Spinal cord injuries in Arkansas due to violence: 1980-1989. Spinal Cord 1997;35:341-8.

14 Chapman S. Over our dead bodies: Port Arthur and Australia's fight for gun control. Annandale: Pluto Press, 1998

15 Athanasou JA, Brown DJ, Murphy GC. Vocational achievements following spinal cord injury in Australia. Disabil Rehabil 1996;18:191-6.

16 Murphy G, Brown D, Athanasou J, et al. Labour force participation and employment among a sample of Australian patients with a spinal cord injury. Spinal Cord 1997;35:23844

17 Walsh J, De Ravin JW. Long term care-disability and ageing. Sydney: The Institute of Actuaries of Australia, 1995.

18 Workcover Corporation. Annual report 1998-1999. Adelaide: Workcover Corporation, 1999 (url: http:/ www.workcover.com)

19 Tate DG, Stiers W, Daugherty J, et al. The effects of insurance benefits coverage on functional and psychosocial outcomes after spinal cord injury. Arch Phys Med Rehabil comes after spin

20 DeVivo MJ, Stover SL, Fine PR. The relationship between sponsorship and rehabilitation outcome following spinal cord injury. Paraplegia 1989;27:470-9.

21 Friesen RW, Ekong CE. Spinal injuries due to front-end bale loaders. Can Med Assoc F 1988;138:43-6.

22 Fildes B, Vulcan P. Neck and spinal injuries: injury outcome and crash characteristics in Australia. In: Griffiths $\mathrm{MJ}$, Brown J, eds. The biomechanics of neck injury - proceedings of a seminar held in Adelaide, Australia. Adelaide: NH\&MRC Road Accident Research Unit, University of Adelaide, Road 1995.

23 Rechnitzer G, Lane J. Rollover crash study — vehicle design and occupant injuries. Report No 65. Melbourne: Monash University Accident Research Centre, 1994.

24 Henderson M, Paine M. Passenger car roof crush strength requirements, $C R$ 176. Canberra: Federal Office of Road Safety, 1998

25 Syson SR. Occupant to roof contact: rollover and drop tests. Advances in occupant protection technologies for the midAdvances in occupant protection technologies for

26 O'Connor PJ. Injury to the spinal cord in motor vehicle traffic accidents. 38th Annual Scientific Meeting of the International Medical Society of Paraplegia, Copenhagen, 1999.

27 National Highway Traffic Safety Administration. Overview of vehicle compatibility/LTV issues. Virginia: US Department of Transportation, 1998

28 Federal Office of Road Safety. The national road safety strategy 2000. Canberra: FORS, 2000. 